\title{
Causes of poor outcome after cataract surgery in Satkhira district, Bangladesh
}

${ }^{1}$ Maidstone \& Tunbridge Wells National Health Service Trust, Maidstone Hospital, Maidstone, UK

${ }^{2}$ International Centre for Eye Health, London School of Hygiene \& Tropical Medicine, London, UK

${ }^{3}$ Child Sight Foundation, Dhaka, Bangladesh

${ }^{4}$ National Institute of Ophthalmology, Dhaka, Bangladesh

${ }^{5}$ CSS Rawm Hospital, Khulna, Bangladesh

Correspondence: H Kuper, International Centre for Eye Health, London School of Hygiene \& Tropical Medicine, Keppel street, London WC1E 7HT, UK Tel: +44 207958 8170; Fax: + 442079588317 . E-mail: hannah.kuper@ Ishtm.ac.uk

Received: 13 July 2006 Accepted in revised form: 20 March 2007 Published online: 13 April 2007

\section{Abstract}

Aims Recent data have raised concerns about visual outcome following cataract surgery. The aim of this study was to assess the frequency and causes of poor and borderline outcome after cataract surgery in a population-based case series in Satkhira district, Bangladesh. Methods A population-based case series was conducted within a population-based cluster survey of people aged over 50 years in Satkhira district where 4868 people underwent visual acuity (VA) screening. Eyes operated for cataract with $\mathrm{VA}<6 / 18$ were examined in detail by an ophthalmologist, including a full history and dilated fundoscopy, to determine the cause of the visual outcome.

Results Cataract surgery was performed on 213 eyes. Outcome was good (VA $>6 / 18)$ for 128 eyes $(60.1 \%$ ), borderline (VA $<6 / 18$ to $6 / 60$ ) for 35 eyes $(16.4 \%)$, and poor $(\mathrm{VA}<6 / 60)$ for 50 eyes (23.5\%) with available correction. Borderline and poor outcomes were most commonly due to lack of spectacles $(\mathbf{2 5 . 8 \%})$, poor selection

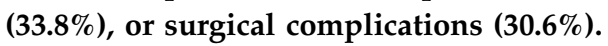

Surgical sequelae, namely posterior capsule opacification, was a less common cause of poor or borderline outcome $(\mathbf{9 . 7 \%})$.

Conclusions Quality of surgical outcomes is of concern in Satkhira district. Increased emphasis on selection of subjects for surgery, provision of spectacles, and monitoring of surgery may improve outcomes.

Eye (2008) 22, 1054-1056; doi:10.1038/sj.eye.6702836; published online 13 April 2007

Keywords: cataract; Bangladesh; surgical outcome; case series

\section{Introduction}

Cataract is the leading cause of blindness worldwide, and is particularly common in
R Lindfield ${ }^{1}$, S Polack ${ }^{2}$, Z Wadud ${ }^{3}$, KA Choudhury ${ }^{4}$, AKMM Rashid ${ }^{5}$ and $\mathrm{H}_{\text {Kuper }^{2}}$ low-income countries. ${ }^{1}$ The number of cataract surgeries performed must be increased to meet this need, while maintaining high-quality surgery. Recent data have raised concerns about visual outcome following cataract surgery, ${ }^{2}$ including surgeries in Bangladesh. ${ }^{3}$ We undertook a population-based case series to investigate the frequency and causes of poor outcome following cataract surgery in Satkhira district, Bangladesh.

\section{Materials and methods}

A population-based cluster survey of visual impairment among people aged over 50 years was conducted in Satkhira district. ${ }^{4}$ A total of 4868 people aged over 50 years underwent VA screening in their homes. The outcome of eyes that had undergone cataract surgery was categorized as: good (VA $>6 / 18)$, borderline $(\mathrm{VA} \geqslant 6 / 60$ but $<6 / 18)$, or poor $(\mathrm{VA}<6 / 60){ }^{2}$ Operated eyes were examined by an ophthalmologist.

Participants gave informed consent. Ethical approval was granted by the Bangladesh Medical Research Council and the London School of Hygiene \& Tropical Medicine. Referrals were made for people with treatable conditions.

\section{Results}

Cataract surgery was performed on 213 eyes (in 170 people). Of these, 117 eyes had extracapsular surgery with an intraocular lens (IOL) implanted (54.9\%) and $96 \mathrm{had}$ intracapsular cataract surgery $(45.1 \%)$.

With available correction, the outcome was good for 128 eyes (60.1\%), borderline for 35 eyes (16.4\%), and poor for 50 eyes (23.5\%) (Table 1). Outcomes improved with best correction, so that with pinhole 144 eyes $(67.6 \%)$ had good 
Table 1 Outcome after cataract surgery

\begin{tabular}{|c|c|c|c|}
\hline \multirow[t]{2}{*}{ Cause } & \multicolumn{3}{|c|}{ Outcome after surgery* } \\
\hline & $\begin{array}{c}\text { Good } \\
(V A \geqslant 6 / 18)\end{array}$ & $\begin{array}{l}\text { Borderline } \\
(V A<6 / 18 \\
\text { to } \geqslant 6 / 60)\end{array}$ & $\begin{array}{c}\text { Poor } \\
(V A<6 / 60)\end{array}$ \\
\hline $\begin{array}{l}\text { Available } \\
\text { correction }\end{array}$ & $128(60.1 \%)$ & $35(16.4 \%)$ & $50(23.5 \%)$ \\
\hline $\begin{array}{l}\text { Best } \\
\text { correction }\end{array}$ & $144(67.6 \%)$ & $26(12.2 \%)$ & $43(20.2 \%)$ \\
\hline
\end{tabular}

Abbreviation: $\mathrm{VA}=$ visual acuity.

outcome, 26 borderline outcome (12.2\%), and

43 poor outcome (20.2\%). Eyes with an IOL implanted

were more likely to have a good presenting outcome than aphakic eyes (OR $=9.1,95 \% \mathrm{CI}=4.6-18.2)$. Eyes operated less than 5 years ago $(n=123)$ were more likely to have a good presenting outcome $(n=123)$ than those operated more than 5 years ago $(n=90)(\mathrm{OR}=2.0,95 \%$

$\mathrm{CI}=1.1-3.6)$.

Of the 85 eyes with poor or borderline outcome, 11 eyes had no $(n=7)$ or inconsistent $(n=4)$ information on cataract surgery and no cause of borderline/poor outcome could be assigned for 12 eyes. Of the remaining 62 eyes, 27 had a borderline outcome and 35 had a poor outcome (Table 2). Sixteen eyes (25.8\%) presented with borderline/poor vision that improved with best correction to $\mathrm{VA} \geqslant 6 / 18$, and were classified as needing spectacle correction. A further 21 eyes $(33.8 \%)$ with borderline/poor outcome were due to selection of cases, mainly those with concomitant macula disease.

Surgical complications were common, and caused $30.6 \%$ of borderline/poor outcome. Surgical sequelae were relatively rare $(9.7 \%)$. The pattern was broadly similar for poor and borderline outcomes, although borderline outcomes were more likely to result from surgical complications and poor outcomes from poor selection.

\section{Discussion}

Outcomes after cataract surgery were of concern in the population-based survey in Satkhira district, ${ }^{3}$ and were far poorer than the WHO recommendation that with available correction only $15 \%$ of eyes should have a borderline outcome and $5 \%$ poor outcome. ${ }^{2}$ Poor or borderline outcomes were largely due to poor selection of cases, surgical complications, or lack of spectacles.

Other case series in South Asia support our finding of unsatisfactory outcome after cataract surgery, particular among aphakics. The Bangladesh national survey identified 226 operated eyes (88\% aphakic), of which $44 \%$ had a good outcome, $28 \%$ borderline, and $28 \%$ poor. $^{3}$
Table 2 Causes of visual impairment in eyes following cataract surgery

\begin{tabular}{lccc}
\hline Cause of VA<6/18 & $\begin{array}{c}\text { Borderline } \\
(V A<6 / 18 \text { to }\end{array}$ & $\begin{array}{c}\text { Poor } \\
(V A<6 / 60)(\mathrm{n}=27)^{\mathrm{a}} \\
(\mathrm{n}=35)^{\mathrm{b}}\end{array}$ & $\begin{array}{c}\text { Total } \\
(V A<6 / 18) \\
(\mathrm{n}=62)\end{array}$ \\
\hline Spectacles & $7(25.9 \%)$ & $9(25.7 \%)$ & $16(25.8 \%)$ \\
$\begin{array}{l}\text { Selection } \\
\quad \begin{array}{l}\text { Macula disease } \\
\text { Glaucomac }\end{array}\end{array}$ & $5(18.5 \%)$ & $13(37.1 \%)$ & $18(29.0 \%)$ \\
$\quad \begin{array}{l}\text { Corneal disease } \\
\text { Surgical }\end{array}$ & 0 & $1(2.9 \%)$ & $2(3.2 \%)$ \\
complications & $12(44.4 \%)$ & $7(20.0 \%)$ & $19(30.6 \%)$ \\
$\begin{array}{l}\text { Surgical sequelae } \\
\text { Posterior }\end{array}$ & $2(7.4 \%)$ & $4(11.4 \%)$ & $6(9.7 \%)$ \\
$\begin{array}{l}\text { capsule } \\
\text { opacification }\end{array}$ & & & \\
\hline
\end{tabular}

Abbreviation: $\mathrm{VA}=$ visual acuity.

aExclusions: six eyes had unclear diagnosis and two had inconsistent or unavailable information on surgery.

${ }^{b}$ Exclusions: six eyes had unclear diagnosis and nine had inconsistent or unavailable information on surgery.

${ }^{\mathrm{c}} \mathrm{Cup}$ disc ratio $<0.5$ and optic disc pallor.

Lack of spectacles and coincident disease were the leading causes of poor/borderline outcome. A case series of 216 operated eyes in Nepal ( $84 \%$ aphakics) found that presenting outcome was good in $43 \%$ of eyes examined, borderline in $26 \%$, and poor in $31 \% .^{5}$ The largest cause of poor outcome was lack of spectacles, followed by surgical complications, and poor selection of cases, while poor outcome due to posterior capsule opacification was rare. The national survey of blindness in Pakistan identified 1788 operated eyes, of which outcome was good in $30 \%$, borderline in $36 \%$, and poor in $34 \% .{ }^{6}$ Again, refractive error was the dominant cause of poor/ borderline outcome, followed by surgical complications and concomitant diseases.

The totality of the evidence points to clear recommendations for improving visual results of cataract surgery. There is an urgent need to distribute spectacles routinely after surgery. Those with concomitant disease who will not benefit from surgery should not needlessly be given operations. There is a continued need for high-quality training of surgeons to reduce complications during surgery. The quality of surgery can also be improved through routine monitoring to inform and improve clinical practice. ${ }^{7,8}$

In conclusion, quality of surgical outcomes is of concern in this population-based case series in Satkhira district. Increased emphasis on selection of subjects for surgery, provision of spectacles, and monitoring of surgery may improve surgical outcomes. 


\section{Acknowledgements}

This research was funded jointly by Christian Blind Mission, Sight Savers International, and ORBIS International.

\section{References}

1 Resnikoff S, Pascolini D, Etya'ale D, Kocur I, Pararajasegaram $\mathrm{R}$, Pokharel G et al. Global data on visual impairment in the year 2002. Bull World Health Organ 2004; 82: 844-851.

2 World Health Organization. Informal consultation on analysis of blindness prevention outcomes. WHO/PBL/98.68. WHO: Geneva, 1998.

3 Bourne RRA, Dineen BP, Ali SM, Noorul Huq DM, Johnson GJ. Outcomes of cataract surgery in Bangladesh: results from a population based nationwide survey. $\mathrm{Br} \mathrm{J}$ Ophthalmol 2003; 87: 813-819.
4 Mathenge W, Kuper H, Polack S, Onyango O, Nyaga G, Limburg $\mathrm{H}$ et al. Rapid assessment of avoidable blindness in Nakuru district, Kenya. Ophthalmology 2007; 114: 599-605.

5 Pokharel GP, Selvaraj S, Ellwein LB. Visual functioning and quality of life outcomes among cataract operated and unoperated blind populations in Nepal. Br J Ophthalmol 1998; 82: 606-610.

6 Bourne RR, Dineen BP, Jadoon Z, Lee PS, Khan A, Johnson GJ et al. Outcomes of cataract surgery in Pakistan: results from The Pakistan National Blindness and Visual Impairment Survey. Br J Ophthalmol 2007; 91: 420-426.

7 Limburg H, Foster A, Gilbert C, Johnson GJ, Kyndt M, Myatt M. Routine monitoring of visual outcome of cataract surgery. Part 2: results from eight study centres. $\mathrm{Br} J$ Ophthalmol 2005; 89: 50-52.

8 Limburg H, Foster A, Gilbert C, Johnson GJ, Kyndt M. Routine monitoring of visual outcome of cataract surgery. Part 1: development of an instrument. Br J Ophthalmol 2005; 89: 45-49. 